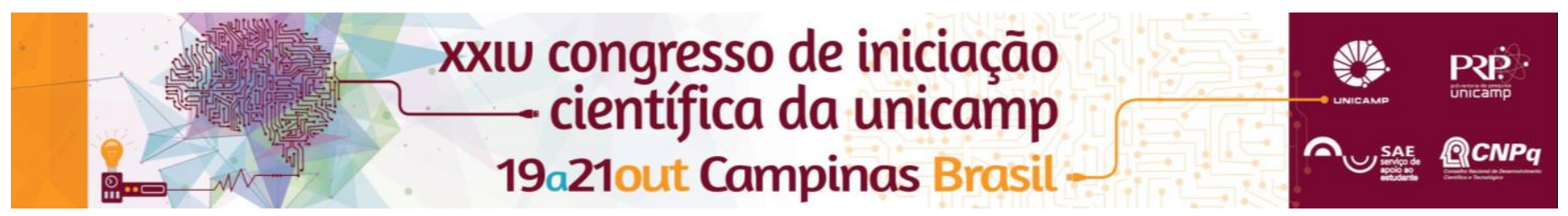

\title{
Desafios e Obstáculos no Desenvolvimento de Tecnologias para a Utilização Sustentável e Econômica de Biomassa
}

\section{Jéssica Cristina do Rosário Ferreira}

\section{Resumo}

O objetivo central deste trabalho foi avaliar, a partir de uma análise cluster não-hierárquica com base no algoritmo kmeans (método AHP), a percepção dos diferentes stakeholders do setor de biocombustíveis (etanol 1G e 2G) em relação ao desenvolvimento da indústria brasileira neste ramo no médio prazo.

\section{Palavras-chave: \\ biocombustíveis, $k$-means, biomassa.}

\section{Introdução}

O trabalho buscou a detectar qual a percepção dos stakeholders em relação ao desenvolvimento da indústria brasileira de biocombustíveis. A principal fonte de dados foram entrevistas e apresentações realizadas durante 0 evento Ethanol Summit 2015. Foram classificados 4 tipos de stakeholders: 1) Pesquisa e Ciência; 2) Indústria e Inovação; 3) Formuladores de política; 4) Usinas de Cana. As entrevistas foram guiadas por questões estruturadas que podem ser aglomeradas em dois grandes temas:1) Projeção de expansão do consumo de etanol; 2) Projeção de progresso tecnológico no setor de biocombustíveis. O conjunto de informações capturado nas entrevistas foi classificado de acordo com uma escala Likert que atribuiu valores entre +1 e +5 às expectativas dos stakeholders de diferentes setores institucionais e, a partir de uma análise não-hierárquica com base no algoritmo $k$-means, formaram-se grupos de opiniões a partir da similaridade ou distância entre as expectativas dos grupos de stakeholders entrevistados, classificando-os entre pessimistas e otimistas.

\section{Resultados e Discussão}

O modelo em curso de organização da indústria brasileira de biocombustíveis $2 \mathrm{G}$ reúne características não replicáveis em nenhuma outra economia nacional. A ampla disponibilidade de matéria-prima com baixo custo de oportunidade e o nível avançado de desenvolvimento do mercado nacional de biotecnologia resulta em elevados ganhos de competitividade às firmas de biocombustíveis $2 \mathrm{G}$ instaladas no país.

Para avaliar o cenário dos biocombustíveis desde o ponto de vista dos agentes que o compõe, o presente trabalhou adotou a metodologia não-hierárquica, que tem como base 0 algoritmo de k-médias. O método de agrupamento foi utilizado para auferir a similaridade ou distância entre as expectativas dos stakeholders entrevistados, classificando-os entre pessimistas e otimistas. Tal exercício visa identificar obstáculos e oportunidades percebidos pelos diferentes stakeholders que compõem os grupos.

As entrevistas foram guiadas por dois eixos: i) projeção de expansão do consumo de etanol e ii) projeção de progresso tecnológico no setor de biocombustíveis.

As projeções correspondem às expectativas com relação à demanda nacional de etanol, aos custos dos insumos na produção de etanol, aos custos totais da produção de etanol, à produtividade de etanol em litros por hectare, à produtividade agrícola etc. As informações e os valores das projeções foram retiradas da base estatística do Portal Nova Cana. Os entrevistados foram incentivados a atribuir valores de +1 até +5 para cada pergunta, sendo que 0 valor +5 corresponde a maior probabilidade de 0 setor alcançar as projeções.

Os representantes de setores institucionais foram classificados em 4 tipos de stakeholders: 1) Pesquisa e Ciência - agentes que desempenham atividades de pesquisa básica, formação e treinamento de recursos humanos; 2) Indústria e Inovação - os que atuam em todas as etapas do processo de inovação e geralmente são ofertantes de tecnologias ao setor; 3) Formuladores de Políticas - com capacidade de decisão sobre o financiamento de P\&D executada por demais agentes da cadeia e 4) Usinas de Cana - são os agentes ofertantes de biocombustíveis, demandantes de inovações.

\section{Conclusões}

Os resultados da pesquisa indicaram que $36 \%$ da amostra formada, majoritariamente, por stakeholders do grupo Pesquisa e Ciência mostrou-se pessimistas em relação ao cumprimento das projeções de expansão de mercado e progresso tecnológico. Fatores como a descontinuidade de políticas de incentivo a P\&D e a expansão do mercado de biocombustíveis foram apontados como justificativas para a posição pessimista. Uma proposta para sanar esse pessimismo seria a implementação de mecanismos com o papel de produzir e garantir maiores ganhos de eficiência e aceleramento do processo de difusão, a intervenção e incentivos se fazendo necessários haja vista que estas transformações não ocorrem espontaneamente.

A grande maioria da amostra mostrou-se otimista, com cluster compreendendo $64 \%$ dos entrevistados. Demonstrando que há agentes que acreditam que, apesar dos inúmeros percalços e defasagem de políticas de assistência, ainda se enxerga grandes potencialidades para a produção de biocombustíveis no Brasil.

MILANEZ, A. Y. et al. O déficit de produção de etanol no Brasil entre 2012 e 2015: determinantes, consequências e sugestões de política. BNDES Setorial, n. 35, p. 277-302. BNDES, Rio de Janeiro, mar. 2012

SILVEIRA, J. M., FULTINO, A. M. E OLALDE, A. R. "Biotecnologia: corporações, financiamento da inovação e novas formas organizacionais." Revista Economia e Sociedade, $n^{\circ}$ 18, 2002. 